Journal of Asian Scientific Research

$\operatorname{ISSN}(e): \quad 2223-1331$

$\operatorname{ISSN}(p): \quad 2226-5724$

DOI: $10.18488 /$ journal.2.2018.84.152.170

Vol. 8, No. 4, 152-170

(C) 2018 AESS Publications. All Rights Reserved.

URL: wrw.aessweb.com

\title{
UNITED PEOPLE: DESIGNING A NEW MODEL OF GLOBAL GOVERNANCE
}

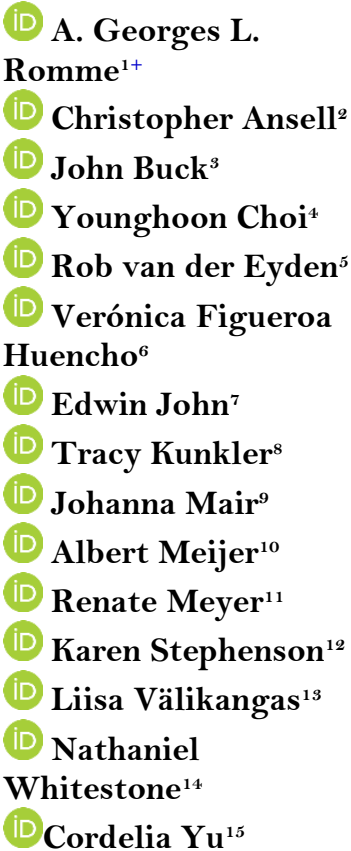

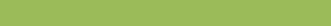

Article History

Received: 25 April 2018 Revised: 14 May 2018

Accepted: 16 May 2018

Published: 18 May 2018

\section{Keywords}

Global governance

Idealized design

Circularity

Collaborative decision-making

Resilience

Informed consent
'Professor of Entrepreneurship \& Innovation, Eindhoven University of Technology, Netherlands.

Email:a.g.l.romme@tue.nl Tel:+31402472014

${ }^{2}$ Professor of Political Science, University of California, Berkeley, USA.

Email:cansell@berkelev.edu Tel:+1510642632.

${ }^{s}$ GovernanceAlive \& Center for Dynamic Community Governance, USA.

Email:john.buch@sociocracyconsulting.com Tel:+14102458654

${ }^{4}$ Professor of Public Administration, Kwangwoon University, South-Korea.

Email:cyhoon@,hw.ac.kr.Tel:+8229404279

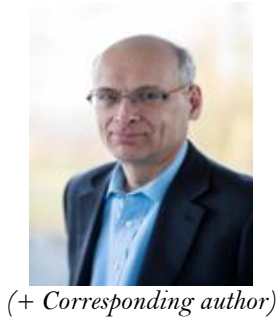

${ }^{5}$ The Sociocracy Group, Netherlands.

Email:rvanderevden@sociocratie.nl Tel:+31621157634

${ }^{6}$ Professor \& director of University of Chile's School of Government ${ }^{\circ}$ Public Management, Chile.

Email:v.figueroa.h@iap.uchile.cl Tel:+56229771468

${ }^{7}$ Neighborhood Community Network; initiator of Neighborhood Parliaments project (India).

Email:edwinmjohn@gmail.com Tel:+914652278223

${ }^{8}$ Circle Forward Partners \& Healthy Power Alliance, USA.

Email:tracy@circleforward.us Tel:+18282428199

${ }^{\circ}$ Professor of Organization, Strategy \& Leadership, Hertie School of

Governance, Germany.

Email:1Mair@hertie-school.org.Tel:+4930259219329

${ }^{10}$ Professor of Public Innovation, Utrecht University, Netherlands.

Email:a.j.meijer@uu.nl Tel:+31302539568

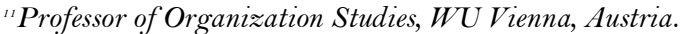

Email:renate.mever@wu.ac.at Tel:+431313364437

${ }^{12}$ Cultural anthropologist, NetForm International, USA.

Email:karen.stephenson@netform.com.Tel:+16464364373

${ }^{13}$ Professor in Innovation Management, Aalto University and Hanken School of Economics, Finland.

Email:liisa.valikangas@aalto.fi Tel:+358504967134

${ }^{n}$ Genius Engine \& Healthy Power Alliance, UK.

Email:ntwhitestone@gmail.com Tel:+447766093015

${ }^{15}$ Content \& Editorial Strategist, Taiwan/USA.

Email:hello@cordeliavu.com Tel:+4252097613

\section{ABSTRACT}

Human-driven changes on this planet have been giving rise to global warming, social instability, civil wars, and acts of terrorism. The existing system of global governance is not equipped to effectively address these enormous challenges. It is slow where one must move quickly, favors bureaucracy and politics over authentic deliberations and effective interventions, and caters to power-brokers and mega-corporations. The world therefore needs a model of global governance that serves to make and implement collectively binding decisions that acknowledge the interests of all those affected, including future generations. This governance model must coordinate the work of great (e.g. national) powers, and at the same time enable billions of people to bring their intelligence and creativity to bear on these challenges. In many ways, the quest for a 
Grand challenge

United Nations

JEL Classification

O50; $\mathrm{P} 40 ; \mathrm{P} 45$. new system of global governance is a grand societal challenge in itself. In this paper, we draw on idealized design to develop an ideal model of global governance and explore the collective search and experimentation efforts it implies. This so-called United People (UP) model involves a circular hierarchy in which power and communication flow in ways that help the global community to effectively address transnational challenges and problems. It involves several, relatively small, governance bodiesrather than a large parliamentary assembly that tends to cripple responsive decisionmaking. The UP model also serves to effectively uncover and address power abuse, simplify the financial household of global governance, and support systemic forms of collaboration with NGOs and other organizations.

Contribution/ Originality: The paper's primary contribution is to develop a blueprint for one of the most critical challenges the world is facing today: the current system of global governance (incl. United Nations) is not equipped to handle major problems such as global warming, social instability, civil wars, and acts of terrorism.

\section{INTRODUCTION}

Imagine the rise of global collaborative governance networks that tap the wisdom of all the people on earth and enable global cooperative solutions needed to address grand challenges. Also imagine these global networks being connected to a small global governance body, rather than a large assembly that tends to cripple responsiveness and decision-making. Each member of this body would be selected and appointed based on a track record of moral leadership — guided by the good of all humankind rather than personal or national interests: think of people like $\mathrm{Al}$ Gore, Angela Merkel, Fazle Hasan Abed, Juan Manuel Santos and Malala Yousafzai. This governance body would make collectively binding decisions on global challenges such as climate change and civil wars. It would be accountable to every person on earth, by means of communication channels that flow from the local to the global level. And it would be able to activate knowledge distributed across the world to prepare decisions. What model of global governance makes this possible? The United People (UP) model addresses this question. Human-driven change transforms our lives and biosphere faster every year, bringing us tremendous wealth (in some parts of the world), extended lifespans, and technological capabilities - but also giving rise to global warming, rapid population growth, social instability, civil wars, and acts of terrorism. The existing system of global governance is not equipped to effectively address these enormous challenges. It is slow where we must move quickly, favors bureaucracy and politics over authentic deliberations and effective interventions, and caters to power-brokers and mega-corporations. As a result, the current system for global governance system fails to live up to its own standards and values (e.g. those expressed in UN Sustainable Development Goals).

We therefore need a model of global governance and collaborative problem solving, which serves to make and implement collectively binding decisions that acknowledge the interests of all those affected, including future generations. This governance model must coordinate the work of great (e.g. national) powers, and at the same time enable billions of people to bring their intelligence and creativity to bear on these challenges.

In many ways, the quest for a new system of global governance is a grand challenge itself, requiring a collective response of many actors interacting constructively over prolonged timespans. We address this challenge in this paper by developing a blueprint of the "ideal" target solution and outlining the collective search and experimentation efforts it calls for. The method adopted to develop this proposal is also known as idealized design, which implies one imagines what the ideal solution can be and then works backward to the situation today [1] This is a way of thinking about complex problems that ensures one does not erect imaginary obstacles, before even knowing what the ideal target solution is Romme [2]. The United People (UP) model draws on principles of valuebased and collaborative governance, authentic deliberation, informed consent, circularity of power, hierarchy, heterarchy, transparency, and resilience. These principles serve to design a model that supports the learning cycle of developing and implementing broad policy frameworks, within which local units meet goals by using their discretion. The UP model involves a circular hierarchy in which power and communication flow in ways that help 
the global community to effectively address transnational challenges and problems. It involves several, relatively small, governance bodies - rather than a large parliamentary assembly that tends to cripple responsive decisionmaking. A key element of the UP model is that decision-making bodies are double linked by way of both an executive and a delegate connection. In this respect, the UP model serves to drastically simplify the infrastructure for global governance, by creating a circular hierarchy that provides a maximum level of resilience and adaptability in both policy making and executive processes. It provides a network of interlinked, relatively small bodies in which authentic deliberation and value-based governance can take place without crippling delays and without key actors secretly pursuing their own interests. The team of authors proposing the UP model in this article involves leading professors as well as practitioners in the area of global governance, humanitarian aid, peace missions, innovation management, leadership, systemic transformation, facilitation skills, and organization design.

\section{DESCRIPTION OF MODEL}

The prospects of life on our planet are not good, due to global warming, rapid population growth, civil wars and acts of terrorism, growing inequalities between people, and extreme poverty in many parts of the world [3-5]. We therefore need new forms of governance which serve to make and implement collectively binding decisions that acknowledge the interests of all those affected, including future generations [5]. The existing system for global governance is not up to the task. As a result, grand challenges such as global warming are addressed via multilateral negotiations, largely driven by the interests of powerful nations and/or multinational companies that have become effectively stateless [6-9]. As a consequence, necessary interventions and actions are often taken too late or not at all. Overall, the current global governance system fails to live up to its own values.

\subsection{Key Principles Informing the Model}

The UP model draws on the following set of principles:

- value-based governance: governance that serves the good of all humankind [10];

- collaborative governance: ways of collaborating (often enabled by digitalization) that allow for a high level of autonomy, heterogeneity and geographical distribution [11-13];

- authentic deliberation: dialogue among (equivalent) decision-makers, who give one another reasons that are mutually acceptable and generally accessible, to take decisions that are binding but open to be challenged in the future [14, 15];

- informed consent: policy decisions are taken when there are no remaining paramount objections to the proposal; 'paramount' here refers to a risk, danger or cost which the decision-makers cannot afford [16-20]; as such, informed consent is fundamentally different from consensus and majority rule [21];

- circularity of power: collective responsibility to make policy decisions, implement them, and measure the outcomes in ways that sustain effective policies and adapt (or eliminate) the ineffective ones [22-24];

- hierarchy and heterarchy: hierarchy is a cascading sequence of levels of accountability, involving different degrees of abstraction, through which knowledge and information are filtered, transformed and communicated [25, 26]; when multiple hierarchies closely collaborate with each other, a heterarchy consisting of a network of at least three (or more) separate hierarchies arises, each with its own raison d'être; a heterarchy can accomplish a collective good that is too complex for any hierarchy to effectively achieve on its own [27, 28];

- transparency: all citizens have full access to, and can actually digest, the documents and proceedings of governance bodies, and they can predict the actions taken by public administrators accordingly [29, 30];

- resilience: the organizational capacity, rooted in a culture of awareness, to grasp and handle (early signals regarding potential) crisis dynamics [31,32]. 
These principles also reflect the complex challenges arising from transnational problems, involving many different stakeholders and various sensitivities around representation and sovereignty. In this respect, an experimentalist governance perspective has been developed, involving the following cycle [33]:

- Broad framework goals and provisional metrics. This step is about developing broad policy framework goals by a central unit/body.

- Local units use discretion to meet goals. Local units have the discretion to devise context-specific strategies to meet the broad goals.

- Information pooling - monitoring, evaluation and data tracking. The pooling of information from lower-level units.

- Framework revision. Iterative learning, based on lessons learned at the local level, is critical.

This circular process, visualized in Figure 1, has been a critical success factor in addressing transnational problems in the area of AIDS, ozone, fishing, and human rights [33-35]. Notably, the iterative nature of this process enhances the adaptiveness and resilience of local units, whereas it maintains a basic hierarchy between bodies deciding on broad (policy) frameworks and local units acting on and further shaping these frameworks. Moreover, this governance process thrives on deliberation and reasoning, informed by provisional metrics and information pooling, to revise and improve the framework over time.

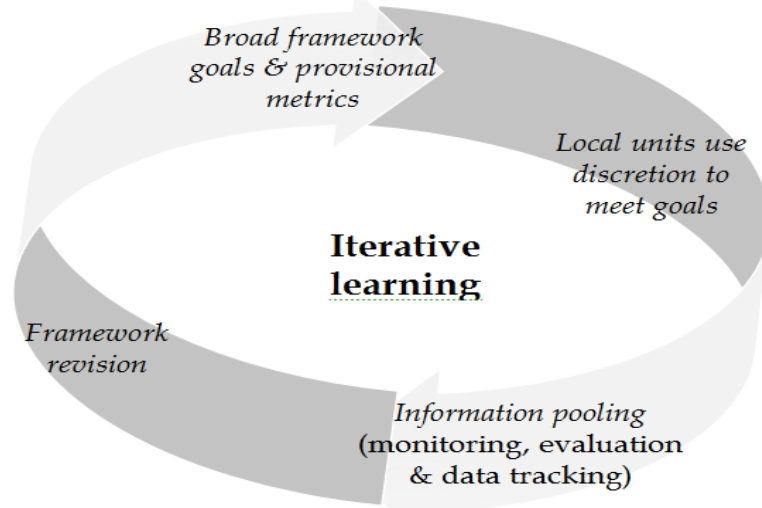

Figure-1. The circular process of experimentalist governance

In the remainder of this proposal, we describe the UP model for making and implementing collectively binding decisions on policy frameworks. This model is designed to fully exploit the circular process of experimentalist governance.

\subsection{The UP Model}

In the UP model, various coalitions work together to address risks and opportunities of global significance. These coalitions help shape, and are also coordinated through, broad (policy) frameworks for global action. These frameworks are developed in a circular hierarchy orchestrated by a small group of moral leaders (in the so-called UP Council), who are chosen by (up to) ten constituent councils created from self-organized networks of people and nations. The UP Council and its Executive Board are the hub of a resilient system for setting and accomplishing framework goals. Figure 2 provides an overview of the model.

Notably, the UP model differs fundamentally from models of world governance previously developed [36] which all involve large assemblies made up of representatives from each nation, similar to the current UN General Assembly. Instead, the UP model reflects the need for relatively small, mandated governance bodies, with the UP Council as final authority in case of disputes and indecisiveness of other international bodies. To a large extent, the model serves to merge the authority and functionality of the UN Security Council with those of the UN General Assembly as well as high-level platforms like the NATO, G7 and G2O. 
A key element of the model is how decision-making bodies are connected by way of both an executive leader (e.g. secretary-general, president) and a delegate link. Whereas the leaders have an executive responsibility in managing a team and/or administrative organization, the chosen delegates and representatives have a pivotal role in enabling and sustaining the cycle of iterative learning (described earlier).

Each arrow represents a person that is a member of both bodies connected by the arrow. Information and power thus flow in both directions, safeguarded by two "linking pins" (e.g. between UP Council and each SC or TC). The UPC also includes the Secretary-General and a representative from Executive Board. The UPC determines the total number of Frameworks as well as the provisional goals and metrics for each Framework.

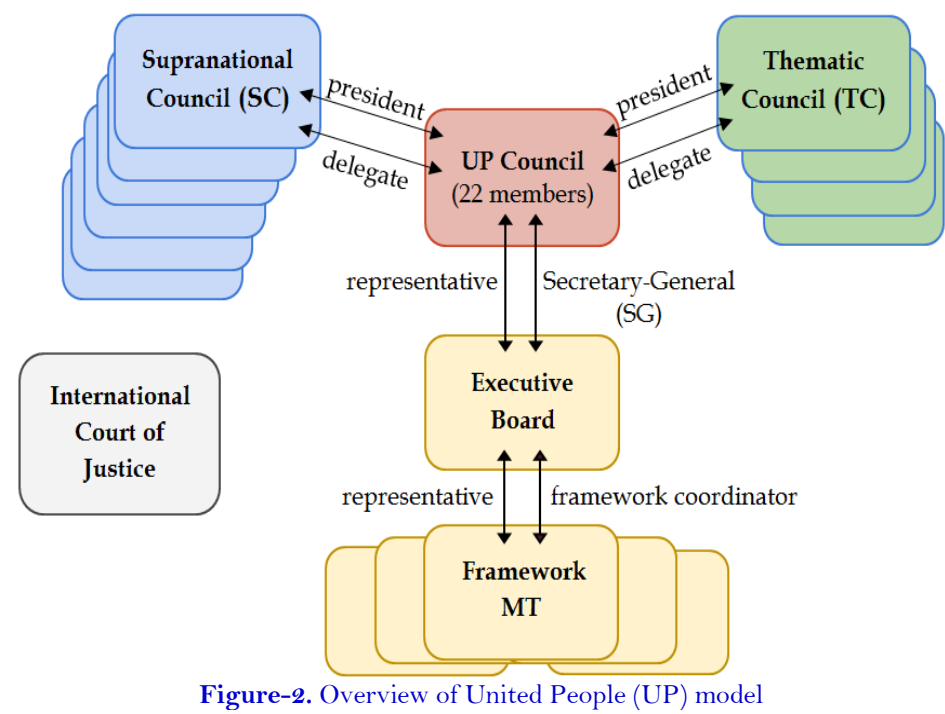

\subsubsection{Policy-Making Bodies}

The UP Council (UPC) is the final decision authority regarding all policy frameworks for transnational problems and challenges which cannot be effectively handled at other (inter)national levels. The UPC has a maximum of 22 members: 10 delegates and 10 presidents of constituent councils, as well as the secretary-general and a representative from the Executive Board (explained later). The UPC makes policy decisions by informed consent and delegates the execution of these decisions.

The UPC is created from up to 10 constituent councils. There are three requirements that any qualifying body, or group of bodies, must satisfy in order to form such a council:

1) Representing and/or Serving: the qualifying bodies forming a council must represent and/or serve a major part of the world population (e.g. at least 500 million people).

2) Purpose and Scope: the council has the explicit purpose of promoting the good of humanity (incl. future generations) and protecting and sustaining our biosphere.

3) Including Everyone and Everything: the entire set of councils connected to the UPC should together represent the entire world population and cover the scope of all key global problems and challenges (cf. the current 17 UN Sustainable Development Goals).

The UP model assumes a maximum of 10 constituent councils, to prevent fragmentation, avoid the need for a large assembly, and motivate nations and other stakeholders to develop critical mass in collaborative ties. The third requirement implies these councils together need to represent the entire world and cover all key transnational problems and challenges.

The primary responsibility of these councils is to identify and monitor global risks and opportunities which their members assess as important or urgent. These councils have secondary responsibilities in raising funds from members and providing a forum through which members may develop agreements on matters that do not require 
global engagement. The deliberative function of these councils is guided by the good and equivalence of all human beings associated with them. A council connected to the UPC can be supranational or thematic in nature.

A Supranational Council (SC) is the main general deliberative forum of a group of nations (such as European Parliament) or a committee created by that forum (cf. European Commission). The EU is likely to constitute such an SC, as is China with several partner countries, and so forth. Depending on the exact threshold defined in the first requirement, 5 to $7 \mathrm{SCs}$ will thus together be able to represent all nations.

The UP model avoids an exclusive focus on the nation-state as core mechanism. Therefore, other qualifying organizations or networks can also be connected to the UPC, in the form of a Thematic Council (TC). Any TC connected to the UPC must have a global thematic orientation.

For example, one TC can be created in the area of poverty, hunger, health and well-being (covering a substantial number of the current UN Sustainable Development Goals). This TC would include representatives of the largest NGOs in the area of medical and humanitarian aid, such as Red Cross, World Vision, and Doctors Without Borders, as well as leading experts in this area (e.g. chosen by a qualifying body of academic institutions), governmental agencies, and businesses. This TC may help coordinate humanitarian activities, similar to what the UN Office for the Coordination of Humanitarian Affairs already does; in the UP model, this TC would also be able to prepare and contribute to framework development via its president and delegate in the UPC.

Another TC would be in the area of Peace and Justice. This TC is likely to be formed by security-related partnerships and military alliances, such as NATO, Islamic Military Alliance (IMA), and Collective Security Treaty Organization (CSTO). Moreover, representatives of global networks focused on mediation, negotiation, and restorative justice can also join this TC. Forming such a TC would be the first step toward well-coordinated investments in military and peace forces across the globe. Moreover, this TC is connected via its president and delegate to the UPC, and thus the latter can more easily and effectively make and implement decisions on policy framework: for example, any UPC decision regarding a peace mission can be more effectively implemented, when the president and delegate of the Peace \& Justice TC were able to raise practical and other concerns in the deliberations preceding this decision. Notably, some qualifying bodies, such as the EU, may have their own policy development processes as well as executive bodies, to address international problems within their own domains. This is beyond the scope of the UP model, which focuses on transnational problems and challenges that cannot be exclusively addressed by other entities (e.g. climate change, civil wars, nuclear threats). Notably, the UP model ensures the structural alignment of policy frameworks of supranational and thematic councils and those of the UPC. It also fully respects the principle of subsidiarity [37] that is, the UPC only takes up and decides on a particular framework or immediate crisis situation, if it cannot be handled by one of the TCs or SCs.

Overall, this part of the UP model invites and promotes global collaboration and alliance formation, in which any established or newly formed collaborative entity can form an SC or TC. This process of creating collaborative councils is open and context-specific, in the sense that each of these councils can be shaped in unique ways-as long as it conforms to the three requirements defined earlier.

\subsubsection{Executive Bodies}

We now turn to the executive side of the model. This side of the model involves a highly adaptive structure, including a single Executive Board (EB) led by the Secretary-General. The UPC will delegate most executive and operational tasks to the $\mathrm{EB}$, but it can also decide otherwise; for example, it can assign the implementation of a particular policy decision to (the executive body of) one or more supranational or thematic councils.

The UPC appoints the Secretary-General (SG) to lead the Executive Board, and as such, the SG also joins the UPC as the functional leader of UP's operations. The SG is selected and appointed from an external pool of candidates; to avoid major conflicts of interest, this pool of candidates excludes all current members of UPC, supranational councils and national governments. The UPC gives the SG the mandate to manage UP's executive 
bodies by setting up administrative systems and processes that enable work within the frameworks authorized by the UPC. As such, the SG is a key link between the UPC and the Executive Board. The UPC monitors all activities conducted within the various frameworks (based on regular reports from the executive board) and, where needed, it adapts frameworks or creates entirely new ones. The Executive Board helps set the agenda of UPC meetings and supervises the work conducted within each framework established by the UPC. The EB also monitors the operations within each framework and regularly submits framework reports to UPC. A key responsibility is to maintain the broad and enabling role of each framework. The 'circularity of power' principle implies that the Executive Board also includes the coordinators of policy frameworks and representatives chosen by the management teams (MTs) of these frameworks. The Framework Coordinators are appointed by the UPC and each Framework MT chooses its representative in the executive board. Evidently, the position of representative (in short: rep) cannot be combined with that of Coordinator.

The size of the EB thus depends on the number of policy frameworks established by the UPC: for example, if 6 frameworks and their management teams are created, the EB is composed of 13 people, including the SG. In this respect, the EB may assign more than one top-level goal to a framework MT; for example, several of the 17 UN Sustainable Development Goals, defined in 2016, might be combined and assigned to a single framework and its MT. The main task of each Framework MT is to sustain broad framework goals that provide sufficient levels of discretion in local units, pool information from various sources, and sustain iterative learning to improve the initial framework. Proposed changes in framework goals and metrics are first discussed by the EB, and then submitted to the UPC. In addition, anyone outside these executive bodies can raise ideas and develop proposals for revising frameworks or developing entirely new ones.

\subsubsection{Overview of Model}

In term of the trias politica, the UP model outlined thus far focuses on the legislative and executive powers at the global level. The third branch of the trias politica is the judiciary one. In the current system, this is the International Court of Justice (ICJ), informally also known as the World Court. The UP model does not imply any major changes for the position of the ICJ.

Overall, the UP model provides a system for making collectively binding decisions that take into account the interests of all those affected, by systematically engaging the intelligence and creativity distributed over the large number of human beings and their organizations on this planet [4]. Moreover, this governance system also serves to signal and address problems at the level where they arise and/or are most pressing. By consequence, more local problems are addressed at other levels - within the boundaries of any relevant laws and policies set at the UP level. Only truly global challenges like climate change, extreme poverty and terrorism are addressed by the UPC.

Figure 2 provides a visual image of the entire model. The UP model drastically simplifies the infrastructure for global governance, in the form of a circular hierarchy that provides a maximum level of resilience and adaptability in both policy making and executive processes. It provides a network of interlinked, relatively small bodies in which authentic deliberation and value-based governance can take place without crippling delays and without key actors being able to secretly pursue national interests.

\subsection{Financial and Other Resources}

The UP model does, initially, not imply any substantial changes in the way the United Nations is currently funded. Any country that wants to operate under the protection of the UP and have access to its resources, makes a financial contribution based on its capacity to pay (largely determined by GNP). Once 5 to 7 Supranational Councils are formed, the funding of the UPC and its executive and support staff can shift to these SCs, and to a lesser extent the TCs: for example, assuming the EU would constitute an SC, the EU then contributes an annual fee to the UP. 
In any case, the UP Council decides how much money each nation (in first scenario) or each SC (in second scenario) must pay. The double links between the UPC and each SC safeguard a sufficient level of commitment to these financial arrangements.

Of course, the second scenario is strongly preferred: the SCs fund all UP's operations, in addition to these SCs (possibly) also developing and funding their own framework activities. In addition, TCs offer complementary resources and capabilities that extend many local activities initiated by UP. This approach is also likely to motivate problem solving at more local levels, involving pilot projects set up around particular issues such as community finance, education, and regional water management, with local funds invested in local initiatives. Activities funded by UP then complement local initiatives or focus on those areas where funds and other resources are absent.

In addition, the UP can draw on various kinds of other (incl. human) resources, for example, those made available by international medical and/or humanitarian organizations and other NGOs; these organizations clearly have a substantial capacity in voluntarily pledging resources, which lessens the need to fund activities via contributions from the SCs. Therefore, the UP model serves to substantially improve the access to, and alignment with, these resources: this is, for example, the case when all globally operating humanitarian and medical NGOs participate in a Thematic Council connected to the UP Council.

In a similar way, the access to and coordination of military and related resources will be greatly improved if an inclusive Thematic Council is formed by all security-related partnerships and alliances (NATO, IMA, CSTO, and so forth). Evidently, inclusiveness is a key requirement for connecting this SC to the UP Council. Such a world-wide collaboration on the military front might substantially reduce the likelihood of accidental conflict escalation, and over time help to put an end to the arms race.

\subsection{E-Democracy and Civil Participation}

The UP model serves to downsize the global governance system to a substantially smaller number of people and bodies, responsible for developing and implementing broad enabling frameworks. This opens up many opportunities to tap into the distributed intelligence and expertise available in various national and regional contexts as well as the numerous pluricentric governance networks that have emerged in the US, Asia, Europe and elsewhere [13, 38-40]. Especially the rise of the internet now enables many people around the world to communicate ideas and observations to other people as well as governance bodies.

The rise of digital networks and, subsequently, networked organizations raises enormous challenges for established public governance systems based on the principle of formal representation. While a few movements, such as the Pirate Party in Germany, Podemos in Spain, and the Net Party of Argentina have been experimenting with tools like "liquid democracy", and reformers in Iceland crowdsourced ideas for their new Constitution, few of these movements have managed to convert digitally-enabled forms of mass engagement into structural changes [41]. These new forms of participation have typically been restricted "to the digital equivalent of suggestion boxes (...), or to the management of small crumbs of public expenditures" [41].

An exceptional case is Taiwan, where about 2000 citizens collaborated to write new legislation via a wellstructured process involving crowd-sourcing of ideas, public surveys and online and in-person meetings [42]. This example demonstrates that it is possible to redesign how large numbers of people give input on complex policy challenges, how democratic bodies listen to this input, and then produce high-quality policy decisions [41]. Socalled facilitators, who provide information to citizens and actively seek broad engagement and input, have been essential to Taiwan's success in e-democracy. For the UP model, the implication is that anyone in the world should be able to identify a transnational problem and/or initiate the process of developing collaborative policy proposals. This requires an online platform (incl. facilitators), to be set up and maintained by the UP. On this platform, UP's key role is to facilitate the discourse around ideas and proposals, and connect the outcomes (regarding entirely new issues or problems within existing frameworks) to the agenda of the appropriate body. 
Figure 3 shows that the participatory process of generating ideas and proposals is a two-way process. Bodies such as the UNC and Executive Board can call for a global online discourse on any particular problem. But, any group of individuals, collaborative network or other actor can also initiate such a process, based on their own initial definition of the problem [43].

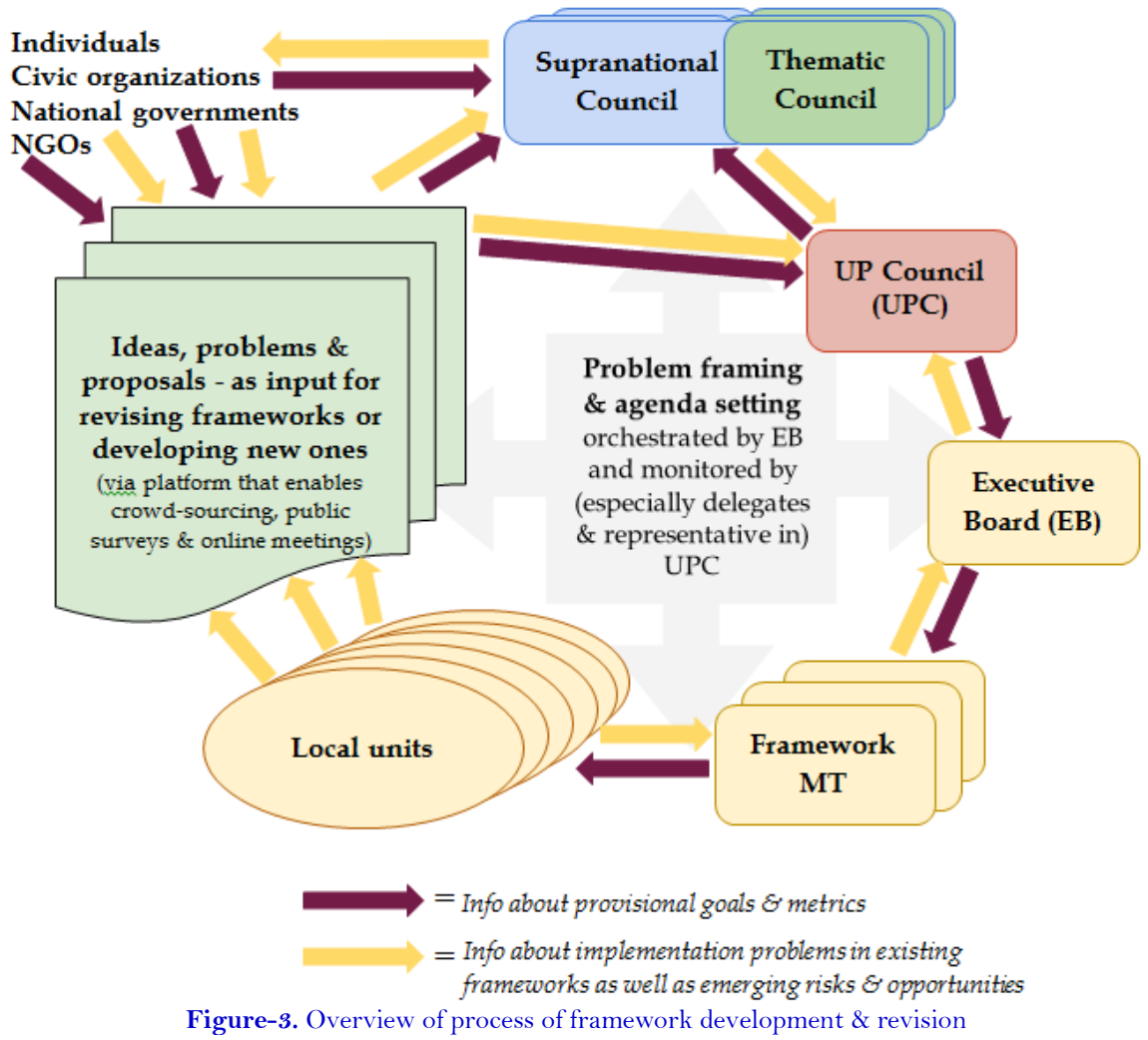

Notably, Figure 3 also visualizes how the circular governance model enables information flows and thereby the process of iterative learning. In this respect, the model is designed to facilitate information flows regarding framework goals and metrics as well as various implementation issues. A similar approach to circular management has been tested in hundreds of companies and other organizations [18, 24, 44].

\subsection{Functions, Responsibilities and Mandates}

The current landscape of global governance includes the UN General Assembly, Security Council, Economic and Social Council, (defunct) Trustee Council, International Court of Justice, as well as many other bodies and platforms such as the G20, G7 and NATO [9]. The UP model serves to simplify this complex landscape of global institutions and platforms, by creating a circular flow of power and information. More specifically, the model involves several, relatively small, bodies for policy making at the supranational and global levels. The central body at the global level is the UP Council, composed of ( $\max ) 22$ people. The UPC also directly monitors UP's executive branch, designed as a resilient corporate structure. The remainder of this section outlines the functions, responsibilities and mandates of each key body in UP model.

\section{UP Council (UPC)}

- Function: main deliberative council of United People (UP) at global level. Its deliberative function is guided by the good of all humankind and by respect for the equivalence of all human beings. The UPC meets every two weeks, but emergency sessions can be called; the UPC can make decisions asynchronously (via a digital platform), if needed. Decisions are taken by informed consent of each member. In the unlikely case 
of a fundamental dispute inside the UPC, it draws on an arbitration committee (consisting of two former UPC members and two outsiders) to resolve the issue. The UPC appoints the four members of this committee, each for a term of 6 years.

- Responsibility: promote global co-operation, create and maintain the international order, and address transnational problems that cannot be addressed elsewhere. A key responsibility of UPC is to develop frameworks that are broad and enabling. The rep from the EB has a critical role here, one that complements the executive role of the secretary-general.

- Mandate: final decisions on broad (enabling) policy frameworks. In addition, the UPC monitors the work conducted within each framework and decides on proposed changes in any deficient framework. A key framework is in the area of Peace \& Justice, in which the EB (and MT of this framework) gets a mandate to intervene in settings where peace, justice and security are at stake. In addition, the UPC also has the mandate regarding any incidental missions or interventions, in cases not foreseen in this particular framework.

\section{Supranational Council (SC) and Thematic Council (TC)}

- Function: main deliberative council of a group of people, nations or organizations. In order to be entitled to be connected to the UPC, the SC or TC has to represent or affect a major part of the world population (the UPC determines the exact threshold). Its deliberative function is guided by the good and equivalence of all human beings represented or served by the council. The council meets at least six times per year, but emergency sessions can also be called.

- Responsibility: promote international cooperation, create and maintain peace and order, and address and solve transnational problems. At the global level, a TC or SC has a key responsibility in identifying and monitoring global risks and opportunities. SCs and TCs also enable and sustain the cycle of iterative learning about policy frameworks, including the alignment with UPC frameworks; here, the council's president and delegate have a critical role as linking pins to the UPC.

- Mandate: the SC or TC can develop and implement its own policy frameworks, within any UPC frameworks in the same policy domain. An SC typically establishes its own executive body (this is outside scope of this proposal); a TC typically coordinates the activities of member organizations that run their own operations. If an SC or TC fails to address a particular transnational problem, the mandate to decide on this problem shifts to the UPC.

\section{Executive Board (EB)}

- Function: UP's key executive body, led by the secretary-general (SG). The EB meets on a weekly basis, but additional (e.g. emergency) meetings can be arranged almost immediately. The EB can also decide asynchronously (via a digital platform), for example on issues that require minimal discussion. Responsibility: the EB helps set the agenda of UPC and supervises the work conducted within each Framework established by UPC. The EB also monitors the operations within each framework and regularly submits framework reports to UPC. A key responsibility is to maintain the broad and enabling role of the frameworks; this is a responsibility shared by the entire EB, but the reps from the MTs have a pivotal role here.

- Mandate: publish the decisions/frameworks established by UPC. Decide on provisional metrics for each framework. Nominate candidates (to UPC) for Framework Coordinator vacancies. Appoint the heads of peacekeeping operations and other missions. Supervise activities within each framework. In addition, implement any incidental (e.g. peace) missions or interventions. 


\section{Framework Management Team (MT)}

- Function: operational management of a framework established by the UPC.

- Responsibility: guide and support the work conducted within the framework by local units. Maintain the broad and enabling role of the framework; this is a responsibility of the entire MT, but the role of the rep (who is also a member of $\mathrm{EB}$ ) is especially critical here.

- Mandate: develop proposals for (changing) the provisional metrics with which the framework is monitored. Allocate resources to local units. Specifically, the MT of the Peace \& Justice framework supports the work conducted by peace missions and other local units operating within this framework; this MT can also support any incidental peace missions or similar interventions that are authorized by UPC and then implemented by EB.

\section{International Court of Justice (ICJ)}

- Function: primary judicial organ at the global level, composed of 15 judges. The UP Council appoints these judges, with informed consent of all its members.

- Responsibility: the ICJ's primary responsibility is to adjudicate disputes among states (e.g. regarding war crimes, illegal state interference, ethnic cleansing) as well as complaints filed against the UNC (e.g. by individual citizens or national governments). Other bodies can call upon the ICJ to provide advisory opinions.

- Mandate: ICJ's mandate largely remains as it is (http://www.icj-cij.org/homepage) also in view of Trias Politica.

The democratic legitimacy of the UP model depends, to a large extent, on how people get elected to join the UP Council, as the key body at the global level, or are appointed at any of the executive positions. The key decision rule here is informed consent. The roles of the reps are complementary to the executive roles of the SG and framework coordinator, as explained earlier: the reps have a pivotal role in enabling and sustaining the cycle of iterative learning. Notably, all appointments are for a term of (maximum) two years, with the opportunity to re-appoint someone in the same position twice. All people are appointed as member of a particular body (incl. any specific roles such as SG) by way of an open discussion, resulting in a decision by informed consent. Some general rules and procedures for appointing people are:

- Members of all bodies are appointed by way of an open discussion in the body authorized to appoint these members, resulting in a decision by informed consent; starting point of this discussion is an online pool of candidates, to which anyone in the world can contribute by nominating and/or endorsing candidates.

- Each body appoints its own chairperson and secretary, by informed consent of all its members; the chair has a key role in facilitating meetings and needs to have proper skills in decision-making based on informed consent.

- Members of all bodies are appointed for a term of two years, with up to two opportunities for reappointment; thus, anyone can fulfill a particular position for maximum period of six years; only members of the arbitration committee (see UPC's function above) are appointed for a term of six years.

- The roles of president and delegate of an SC or TC cannot be combined in a single person, be fulfilled by citizens from the same country, or combined with any other political or executive position at the national or international level.

- The roles of secretary-general and EB representative (in UPC) are incompatible, as are the roles of Framework Coordinator and MT's representative in EB. 


\subsection{Creating Momentum}

The UP model involves an idealized design that invites and enables learning and evolution over time [45]. In this respect, many attempts to renew public governance practices fail, due to the short-term realism prevailing in most political settings [46-48]. Ansell [16] thus recommends a pragmatic and experimentalist approach to consentbased dialogue and collaboration, involving a long-term effort of all stakeholders to build awareness, skills and knowledge. This approach calls for many distributed experiments and pilot projects in which solutions are tested, improved and adapted to local customs and cultures. These experiments and pilots serve to create momentum toward the UP model — probably also redefining it along the way.

The portfolio of effective governance practices, within the envelope of a newly emerging global order, would thus consist of practices at the local, regional, national and supranational levels. To codify these practices and promote learning in this area, an open-source (wikipedia-like) system is needed. This open source-system will include studies of governance practices (at all levels) and manuals and guidelines for decision-making, public accountability, circularity of power, and so forth.

Several additional strategies help to create momentum. First, storytelling is pivotal in digital as well as face-toface settings, and therefore critical to any effort to create momentum and transformation. That is, all communication about the UP model needs to be honest, personalized and visionary, expressing the 'heart and soul' of the endeavor. This is best achieved by delivering clear, concise and relevant stories. Second, social media efforts will enhance the collective intelligence emerging from collaborative efforts and the various partnerships to be developed.

Moreover, there are various ways to try out and demonstrate key elements of the model. Any existing body of the United Nations, or one of its stakeholders, can seek to pilot test (elements of) the UP model. For example, one can:

- try out the decision rule of informed consent in various policy committees and/or executive bodies, to explore how this decision approach creates inclusiveness and commitment, and thus enhances decision-making capacity and effectiveness;

- experiment with the 'double linking' between the UN and other international bodies (as potential Supranational Councils), such as the EU; for example, the European Commission could be linked to the UN via the EU President (who would join meetings at the UN as an advisor) and the UN would appoint an "UN Emissary" to the European Parliament (acting as an advisor there);

- apply the proposed mechanisms of experimentalist governance and public consultation (similar to the Taiwan case) in developing a new framework regarding, for example, the challenges arising from migration and refugee movements in several parts of the world; as such, a well-structured process involving crowd-sourcing of ideas, public surveys, and online as well as face-to-face meetings will serve to develop ideas and, ultimately, a proposal for a new framework in this area;

- use a similar approach in redesigning the UN system, by rewriting the UN Charter in a new UP Charter; this big challenge is also best addressed by means of globally crowd-sourcing of ideas, public surveys, and online as well as face-to-face meetings; the UN Assembly can initiate this process, but it can also be designed and carried by any self-organized group of world citizens.

The UP model focuses on global governance. To mobilize the full potential of the model, global and local governance need to be systemically connected. This can be done by introducing similar structures and approaches in neighborhoods, cities, regions and nations. 


\section{ASSESSMENT OF THE UP MODEL}

This section assesses how the UP model meets various criteria in the area of: core values, decision-making capacity, effectiveness, resources and financing, trust and insight, flexibility, protection against abuse of power, and accountability.

\subsection{Core Values}

Value-based governance is at the heart of the model that is firmly grounded on human dignity and equivalence; in this model, linkages between relatively small councils and other bodies as well as decision-making by informed consent serve to avoid the win-lose dynamics of large-scale elections and parliamentary bodies [18, 24, 49].

The model is also designed to suppress the widespread tendency (among politicians) to act in self-serving ways, rather than in the interest of all humankind. Notably, the UP model serves to contain any national or regional interests at their own level. That is, the SC's delegate and president joining the UP Council may seek to pursue the interests of their SC's stakeholders, but in doing so are constrained by the decision rule of informed consent, which enables other members of the UP Council to correct any self-serving initiatives.

As such, the UP model transforms the United Nations into a role model and benchmark for value-based governance, which may inspire stakeholders at for example municipal, regional and national levels to adopt similar governance practices.

\subsection{Decision-Making Capacity}

The model involves a circular hierarchy made up of relatively small decision-making bodies, double linked to each other. The broad experience with a similar system in the corporate world suggests that delays and veto power are not inhibiting any decisions, because authentic deliberation, circularity, and policy decision-making by informed consent effectively enable each unit to make, implement and monitor decisions that are binding and consistent with higher-level rules and policies [18, 24, 44].

Notably, only decisions on policy frameworks are made by informed consent, especially in the UP Council. These frameworks entail broad goals and provisional metrics, to provide sufficient discretion for Framework coordinators as well as leaders of operational units to decide on various implementation issues. As such, the decision-making speed and responsiveness of local units is high, because they operate within broad frameworks that are designed to enable flexibility and improvisation at the local level.

The risk that decisions on necessary interventions and actions are not taken, or are taken too late, can be substantially reduced by establishing additional rules, such as: if a body does not take a decision by consent, after deliberating up to a maximum of $x$ (e.g. three) meetings on a particular proposal, then the authority to decide on it moves to the next higher body. These rules appear to enhance the decisiveness of a decision-making body, because participants strongly prefer that the authority to decide on a particular topic does not move elsewhere; that is, these additional rules do not motivate participants to shift the responsibility upward [23, 50, 51]. In our model, only the UP Council is not connected to a "higher" body, which makes it so important that the UPC is composed of a relatively small number of moral leaders that take decisions - even when the problem at hand is politically highly sensitive. In the unlikely case of a fundamental dispute within the UPC, the decision authority on that particular issue shifts to an arbitration committee (consisting of two former UPC members and two external people). This is another safeguard of the decision-making capacity of the UP governance model.

\subsection{Effectiveness}

The capability to handle global challenges and risks is maximized, due to the circular flow of power, communication and expertise. Moreover, the circular nature of the governance model implies that policy frameworks are democratically legitimate as well as collectively binding. These broad, enabling frameworks are in 
line with recent insights arising from studies of experimentalist governance [33-35]. That is, these frameworks enable provisional metrics, afford discretion to local units, and enhance iterative learning and framework revision. We illustrate the effectiveness of our model by exploring two current examples of the dysfunctionality of the existing UN system: the Syrian civil war and the global challenges arising from climate change; the former is a "local" issue that ideally needs to be resolved locally, whereas the latter is a global problem requiring a global framework.

In case of the Syrian civil war, the UN Security Council has thus far been unable to intervene, which has shifted the problem to various coalitions acting without any legal legitimacy. In the UP model, the Syrian civil war would initially have to be addressed at the level of the most relevant Supranational Council. That is, this SC can decide on an intervention in the armed conflict in Syria, and implement these actions accordingly. If this SC fails to agree on such an intervention, the decision authority shifts to the UP Council. The UPC can then take action, by using either the existing Peace \& Justice framework (and the resources this framework coordinator has access to) or agree on a set of interventions if such a framework does not exist. In any case, the resulting intervention in Syria would then be completely legitimate in terms of international law, and is also likely to be effective if the leadership of the mission is given sufficient discretion to take the necessary actions and improvise where needed.

The other example is UN's ongoing struggle to come to a global, collectively binding agreement on policies addressing climate change; the preliminary result is the Paris Agreement in which 195 countries in 2015 agreed to a global action plan. The ratification process is currently ongoing, and still far from complete; moreover, the US recently chose to withdraw from their initial signature. In the UP model, any (continued) program addressing climate change will very likely benefit from the new top structure at the global level. The UP Council is not directly coupled to any national interests; that is, the entire membership of the UPC involves delegates and presidents of SCs or TCs that are not directly coupled to any national or industrial interests. Thus, each SC/TC draws on its collective wisdom, safeguarded in the process of decision-making by consent, to choose a president and a delegate who are guided by the good of all humankind. Moreover, the distributed structure of global policy making, visualized in Figure 2, also explicitly allows for different (sub)continental climate agreements, embedded in a broader agreement at the global level. The UPC would then decide on a framework similar to the Paris Agreement (collectively binding for all nations) but also enable, for example, the EU to agree on an additional framework. The latter framework may be much more ambitious in terms of targets for mitigation, adaptation and finance of greenhouse gas emissions.

\subsection{Resources and Financing}

As explained earlier, the UP model does not imply any direct changes in the way the United Nations is currently funded: nations pay a financial contribution based on their capacity to pay. But, once SCs have been formed, the funding of the UP can shift to the SCs. This obviously would enormously simplify the financial household of the United Nations. We have also argued that these financial arrangements will enhance problem solving at more local levels. That is, UPC's frameworks need to focus on complementing local initiatives, or on areas and problems where funds and other resources are absent.

In addition, the UP model implies that global governance bodies have better access to various kinds of other resources. For example, the resources of globally operating NGOs in the area of medical and humanitarian aid, or those of security-related partnerships and military alliances. As we have explained in the Model section, the UP model promotes and enables a global process of collaboration and alliance formation and demotivates competition and collusion between national governments, corporations, NGOs and other stakeholders.

\subsection{Trust and Insight}

A global governance institution that seeks to be transparent and trustworthy must enable all citizens of the world to fully access, and actually digest, its documents and proceedings. Moreover, based on this information, they 
should be able to predict the actions taken by public administrators. Rather than merely (rhetorically) subscribing to the principle of transparency, the UP model creates internal conditions and roles (e.g. of delegates and representatives) that enhance authentic deliberation and open governance as well as promote whistleblowing [16, 24]. In this respect, power and information flow in a circular manner, which safeguards the transparency and accountability of one body toward another. Notably, if this internal transparency is not present, it is impossible to be trustworthy and transparent for more distant stakeholders. For example, the city council in a Dutch municipality first improved the internal transparency of its policy development processes, before it opened and transformed these processes by continually engaging and consulting a large number of citizens [52].

In this respect, the model draws on deep insight into power structures, arising from the sociocratic governance model $[18,24,44]$. It also benefits from the available expertise in creating consent-based organizations that are fully transparent as well as experiences in developing local and regional collaborative entities, based on the principles outlined earlier.

\subsection{Flexibility}

Linkages between national, supranational and global governance bodies tend to be highly inflexible and complex [9]. Instead, the model we propose is rather straightforward, highly resilient, and adaptive. Large parliamentary bodies are absent from the model. Instead, the model entails a set of decision-making bodies that are systemically connected by way of executive and representative linkages, with each body having a clearly defined function and mandate.

In this respect, the UP model is highly flexible, because each of its components can be eliminated, redesigned or adapted without substantial impact on the rest of the system [26]. This flexibility arises from each body being linked to another level via only two connections: the executive and representative/delegate link (see also Figure 2). For example, the UP Council and Executive Board can thus respond quickly to any crisis situation, enabled by one of the current Frameworks (established by the UPC) or by taking a new initiative. A Supranational or Thematic Council can signal any new global risks, and have its delegate in the UPC put it on UPC's agenda. All these agenda setting and decision-making processes involve very short cycles; in the case of an emergency situation, as short as a few days (or even hours).

Finally, regarding policy development, the UPC only has a mandate to establish frameworks in terms of broad (enabling) goals and provisional metrics. This enables local units to use their discretion and devise context-specific strategies and measures. The flexibility of local units is thus maximized, to be able to respond to unexpected situations and improvise where necessary.

\subsection{Protection against Abuse of Power}

The UP model involves a circular hierarchy with the structural reflexivity that is missing in many public governance settings. In the absence of circularity of power, people at key political and executive positions easily become 'prisoners' of their positions. By creating a system of double-linked councils and executive units, the communication flow cannot be monopolized by anyone, such as the secretary-general or presidents of Supranational or Thematic Councils: they are all embedded in a continual process of checks and balances. Evidently, if this new model of global governance has been embraced and tested, it also needs to be safeguarded in a new UP Charter or major changes in the current UN Charter.

Although no governance model can fully eradicate the abuse of power, the UP model does provide conditions in which (early signals of) such an abuse are quickly picked up and addressed. In this respect, studies of circularity of power provide various examples of how whistleblowing in corporate as well as public governance settings become an entirely legitimate component of the dialogical processes informing policy decisions taken by informed consent [23, 24, 52]. In this respect, the power of argument prevails over the power of rank and position. Consequently, 
opposition and counter-argumentation are key mechanisms in improving the quality of policy decisions and thereby the effectiveness and resilience of the entire governance system.

\subsection{Accountability}

The UP model embraces the experimentalist governance perspective, so that the plurality of stakeholders at local levels and the various sensitivities around representation and sovereignty can be addressed in ways that fit the local institutional and cultural setting. Individual people, civic movements and national governments can hold the UP Council (indirectly) accountable via the Supranational or Thematic Councils they are associated with. These councils more directly hold the UP Council accountable, via their delegates in the UPC. In a more formal manner, legal complaints against decisions of the UPC can be filed at the International Court of Justice.

But most importantly, the direct engagement of various stakeholders in UP governance enables both transparency and accountability. In this respect, the UP model involves an online platform (incl. facilitators), to be set up and maintained by the Executive Board. This platform enables a global discourse around current and emerging challenges and risks, and connects it to the agenda of the appropriate body; Figure 3 provides an overview.

Moreover, the UP model is characterized by subsidiarity [37] that is, challenges and issues are handled at the level that is consistent with their resolution. Therefore, the UP Council only takes up and decides on a particular policy framework or immediate crisis situation, if it cannot be handled at a more local level (e.g. region, nation, or supranational/thematic council. In the former case, the UP Council provides support to actors at all levels, through the measures and resources implied by the framework.

\section{CONCLUSION}

The existing system of global governance is not equipped to effectively address challenges such as global warming, rapid population growth, social instability, civil wars, and acts of terrorism. We therefore need a new model of global governance and collaborative problem solving. The United People model developed in this paper provides a blueprint of an ideal target solution. The UP model draws on principles such as value-based governance, authentic deliberation, informed consent, circularity of power, transparency, and resilience. These principles served to design a model that supports the learning cycle of developing and implementing broad policy frameworks, within which local units meet goals by using their discretion. The UP model involves a circular hierarchy in which power and communication flow in ways that help the global community to effectively address transnational challenges and problems. It involves several, relatively small, governance bodies - rather than a large parliamentary assembly that tends to cripple responsive decision-making.

The key body at the global level is the United People Council (UPC), composed of 22 people. The UPC directly monitors its executive operations, designed as a resilient corporate structure (led by UP's secretary-general). The members of the UPC are elected by supranational and thematic councils that are formed by nations, civic movements, or networks of organizations. Up to 10 of these supranational and thematic councils are connected to the UPC. The primary responsibility of these councils is to identify and monitor global risks and opportunities. As such, the UP model invites and promotes a global process of collaboration and alliance formation in which any established or newly formed entity (incl. nations, NGOs, civic movements) can build collaborative ties and form a council. This process of creating collaborative councils is open and context-specific, in the sense that each of these councils can be shaped in unique ways.

A key element of the UP model is that decision-making bodies are double linked by way of both an executive and a delegate connection. Executives have a key responsibility in initiating and supporting operational activities within the policy frameworks established by the UP Council. By contrast, delegates and representatives have a pivotal role in enabling and monitoring the learning cycle of global governance. In this respect, the UP model 
drastically simplifies the infrastructure for global governance, by creating a circular hierarchy that provides a maximum level of resilience and adaptability in both policy making and executive processes. It provides a network of interlinked, relatively small bodies in which authentic deliberation and value-based governance can take place without crippling delays and without key actors secretly pursuing their own interests.

All appointments are for a maximum term of two years, with the opportunity to re-appoint someone in the same position twice. All people are appointed via an open discussion, resulting in a decision by informed consent, rather than consensus or majority rule. Overall, the UP model appears to provide decision-making capacity without crippling delays; ensures effective implementation of decisions; involves a circular hierarchy in which power abuse is quickly uncovered and addressed; includes the power to hold decision-makers accountable; enormously simplifies the financial household of global governance; and enables more systemic forms of collaboration with NGOs and other organizations that have substantial resources.

Most attempts to renew public governance practices fail due to short-term realism and opportunism. Any attempt to re-design global governance therefore requires a long-term effort in building awareness, skills and knowledge, as well as many distributed experiments and pilot projects in which new governance approaches are tested, improved and adapted. This collective effort allows stakeholders to interact and engage in multiple experiments, inspired by the UP model. Moreover, this approach serves to create momentum toward a new governance system that can redefine itself along the way. An open-source system that reports findings from pilot projects and studies of changes in governance practices can be a key driver of this collective effort.

Funding: This study received no specific financial support.

Competing Interests: The authors declare that they have no competing interests.

Contributors/Acknowledgement: All authors contributed to this study. More background information on the UP model is available at: https://www.researchgate.net/publication/324747314_Appendix_to_United_People

\section{REFERENCES}

[1] R. L. Ackoff, J. Magidson, and H. J. Addison, Idealized design: How to dissolve tomorrow's crisis today. San Francisco, CA: Wharton School Publishing, 2006.

[2] A. G. L. Romme, "Action research, emancipation and design thinking," Journal of Community and Applied Social Psychology, vol. 14, pp. 495-499, 2004. View at Google Scholar | View at Publisher OECD, Bridging the gap: Inclusive growth 2017 update report. Paris: OECD, 2017. G. Shkliarevsky, "Rethinking democracy: A systems perspective on the global unrest," Systems Research and Behavioral Science, vol. 33, pp. 452-470, 2016. View at Google Scholar | View at Publisher L. Szombatfalvy, The greatest challenges of our time. Stockholm: Ekerlids, 2010.

[6] M. Barnett, Eyewitness to a genocide: The United Nations and Rwanda. Ithaca, NY: Cornell University Press, 2002. P. Khanna and D. Francis, "These 25 companies are more powerful than many countries," Foreign Policy, vol. $15,2016$. View at Google Scholar

[8] M. Lipson, "Peacekeeping: Organized hypocrisy?," European Journal of International Relations, vol. 13, pp. 5-34, 2007. View at Google Scholar

[9] M. Jiborn and F. Tersman, The current shape of global governance - a look inside the UN structure. In: Leyre, J. (ed.), Remodelling global cooperation: Global challenges quarterly risk report. Stockholm: Global Challenges Foundation, 2016.

[10] D. Gauthier, Morals by agreement. Oxford: Oxford University Press, 1986.

[11] C. Ansell and A. Gash, "Collaborative governance in theory and practice," Journal of Public Administration Research and Theory, vol. 18, pp. 543-571, 2008. View at Google Scholar

[12] K. Emerson, T. Nabatchi, and S. Balogh, "An integrative framework for collaborative governance," Journal of Public Administration Research and Theory, vol. 22, pp. 1-29, 2011. View at Publisher 
[13] K. Stephenson, Rethinking governance: Conceptualizing networks and their implications for new mechanisms of governance based on reciprocity. In: T. Williamson (ed.), The handbook of knowledge-based policing: Current conceptions and future directions. San Francisco, CA: Wiley, 2008.

[14] J. Bessette, The mild voice of reason: Deliberative democracy \& american national government. Chicago: University of Chicago Press, 1994.

[15] A. Gutmann and D. Thompson, Why deliberative democracy? Princeton, NJ: Princeton University Press, 2002.

[16] C. K. Ansell, Pragmatist democracy: Evolutionary learning as public philosophy. Oxford: Oxford University Press, 2011.

[17] J. M. Buchanan and G. Tullock, The calculus of consent. Ann Arbor: University of Michigan Press, 1962.

[18] J. Buck and S. Villines, We the people: Consenting to a deeper democracy. Washington, DC: Perfect Paperback, 2007.

[19] R. Likert, The human organization. New York: McGraw-Hill, 1976.

[20] A. Sen, "Rationality and social choice," American Economic Review, vol. 85, pp. 1-24, 1995. View at Google Scholar

[21] Appalachian, "Appalachian foodshed project," A Regional Report on Community Food Security: West Virginia, Appalachian North Carolina and Virginia, 2016.

[22] R. L. Ackoff, The democratic corporation. New York: Oxford University Press, 1994.

[23] A. G. L. Romme, "Domination, self-determination and circular organizing," Organization Studies, vol. 20, pp. 801-832, 1999. View at Google Scholar $\mid$ View at Publisher

[24] G. Romme, The quest for professionalism: The case of management and entrepreneurship. Oxford: Oxford University Press, 2016.

[25] E. Jaques, "In praise of hierarchy," Harvard Business Review, vol. 68, pp. 127-133, 1990.

[26] H. A. Simon, The organization of complex systems. In: H.H. Pattee (ed.), Hierarchy theory: The challenge of complex systems. New York: George Braziller, 1973.

[27] J. E. Innes and D. E. Booher, Collaborative policymaking: Governance through dialogue. In: Hajer, M.A. छ Wagenaar, H. (eds.), Deliberative policy analysis: Understanding governance in the network society. Cambridge: Cambridge University Press, 2003.

[28] K. Stephenson, Heterarchy. In: C. Ansell \& J. Torfing (eds.), Handbook on theories of governance. Cheltenham, UK: Edward Elgar, 2016.

[29] M. Kornberger, R. E. Meyer, C. Brandtner, and M. A. Höllerer, "When bureaucracy meets the crowd: Studying 'open government' in the Vienna city administration," Organization Studies, vol. 38, pp. 179-200, 2017. View at Google Scholar View at Publisher

[30] A. J. Meijer, D. Curtin, and M. Hillebrandt, "Open government: Connecting vision and voice," International Review of Administrative Sciences, vol. 78, pp. 10-29, 2012. View at Google Scholar | View at Publisher

[31] G. Hamel and L. Välikangas, "The quest for resilience," Harvard Business Review, vol. 81, pp. 52-63, 2003.

[32] L. Välikangas, The resilient organization: How adaptive cultures thrive even when strategy fails. New York: McGraw-Hill, 2010.

[33] C. Ansell and G. Goldstein, "Experimentalist governance in global public health: The case of UNAIDS," Unpublished Working Paper, 2017.

[34] G. De Burca, R. O. Keohane, and C. F. Sabel, "New modes of pluralist global governance," New York University Journal of International Law and Politics, vol. 45, pp. 723-786, 2013. View at Google Scholar

[35] C. F. Sabel and J. Zeitlin, Experimentalist governance. In: D. Levi-Faur (ed.), The Oxford handbook of governance. New York: Oxford University Press, 2012.

[36] GCF, Global governance models in history. Stockholm: Global Challenges Foundation (GCF), 2017.

[37] UNDP, "Decentralization: A sampling of definitions." Retrieved from http://web.undp.org/evaluation/documents/decentralization_working_report.PDF, 1999.

[38] E. Ferlie, L. Fitzgerald, G. McGivern, S. Dopson, and C. Bennett, "Public policy networks and 'wicked problems': A nascent solution?," Public Administration, vol. 89, pp. 307-324, 201 1. View at Google Scholar | View at Publisher 
[39] MSI, "The multi-stakeholder Initiative (MSI) database." Retrieved http://www.msi-integrity.org, 2017.

[40] S. Waddell, Global action networks: Creating our future together. New York: Palgrave Macmillan, 2011.

[41] L. Barry, "VTaiwan: Public participation methods on the cyberpunk frontier of democracy. Retrieved from https://civichall.org/civicist/vtaiwan-democracy-frontier/," 2016.

[42] E. Tang, "Uber responds to vTaiwan's coherent blended volition." Retrieved from https://blog.pol.is/uber-respondsto-vtaiwans-coherent-blended-volition-3e9b75102b9b, 2016.

[43] O. Berthod, G. Müller-Seitz, and J. Sydow, "Out of nowhere? Interorganizational assemblage as the answer to a foodborne disease outbreak," Schmalenbach Business Review, vol. 66, pp. 385-414, 2014. View at Google Scholar | View at Publisher

[44] A. G. L. Romme and G. Endenburg, "Construction principles and design rules in the case of circular design," Organization Science, vol. 17, pp. 287-297, 2006. View at Google Scholar | View at Publisher

[45] S. L. Jarvenpaa and L. Välikangas, "From governance void to interactive governing behaviors in new research networks," Academy of Management Discoveries, vol. 2, pp. 226-246, 2016. View at Google Scholar | View at Publisher

[46] A. Meijer, R. van der Veer, A. Faber, and J. Penning de Vries, "Political innovation as ideal and strategy: The case of aleatoric democracy in the City of Utrecht," Public Management Review, vol. 19, pp. 20-36, 2017. View at Google Scholar View at Publisher

[47] R. E. Meyer and G. Hammerschmid, "Changing institutional logics and executive identities: A managerial challenge to public administration in Austria," American Behavioral Scientist, vol. 49, pp. 1000-1014, 2006. View at Google Scholar $\mid$ View at Publisher

[48] A. Michels, "Innovations in democratic governance: How does citizen participation contribute to a better democracy?," International Review of Administrative Sciences, vol. 77, pp. 275-293, 2011. View at Google Scholar $\mid$ View at Publisher

[49] G. Endenburg, Sociocracy: The organization of decision-making. Delft: Eburon, 1998.

[50] A. G. L. Romme and A. van Witteloostuijn, "Circular organizing and triple loop learning," Journal of Organizational Change Management, vol. 12, pp. 439-453, 1999. View at Google Scholar | View at Publisher

[51] P. van der Meché, J. Coldewey, and H. Esser, "Decision making systems matter AgileAlliance.org." Retrieved from https://www.agilealliance.org/wp-content/uploads/2016/07/DecisionMakingSystems.pdf, 2016.

[52] A. G. L. Romme, J. Broekgaarden, C. Huijzer, A. Reijmer, and R. A. I. van der Eyden, "From competition and collusion to consent-based collaboration: A case study of local democracy," International Journal of Public Administration, vol. 41, pp. 246-255, 2018. View at Google Scholar | View at Publisher

Views and opinions expressed in this article are the views and opinions of the author(s), Journal of Asian Scientific Research shall not be responsible or answerable for any loss, damage or liability etc. caused in relation to/arising out of the use of the content. 